education and research and by stimulating prevention in the field of burn care.

Recently, we held our first pilot course in Essential Burn Care in Karachi, Pakistan, which was very well received and we aim to develop this course further and expand its availability initially in the Indian subcontinent and then further afield. This is a very practical course that concentrates on the initial phases of burn care with particular emphasis on mild to moderate burns which form the vast majority of burn injuries worldwide. We are also building up our educational website and have produced our first bilingual (English and Urdu) educational DVD on early excision and grafting of minor burns. INTERBurns has also awarded grants to burn professionals in all three partner countries to attend and present at international meetings and undergo short training fellowships.

\section{International network for training, education and research in burns}

\author{
Dear Sir, \\ In these days of increasing global tension and disharmony, \\ I would like to bring to your attention an example \\ of friendship and international cooperation with a \\ humanitarian mission.
}

INTERBurns (International Network for Training, Education and Research in Burns) is a partnership that has developed between the Welsh Centre for Burns and Plastic Surgery, Wales, UK, Choithram Surgical Research Institute Burns Centre, Indore, India and Dow University Medical College Burns Centre, Karachi, Pakistan.

Whilst burn injuries may be decreasing in some parts of the world, there are still enormous global disparities between the incidence and also the morbidity and mortality associated with burn injury. It is estimated that $90 \%$ of burn injuries occur in developing countries and $70 \%$ of these are in children. Whilst burns of $90 \%$ regularly survive in the world's best centres, survival of a patient with more than $40 \%$ TBSA is rare in the vast majority of the world.

INTERBurns has been established to address the needs of the majority of burn victims and those who treat them, in resource-poor countries of the world. Our mission is to reduce the global burden of burn-related death and disability by disseminating knowledge through training,
As doctors and burn professionals, we believe we have a duty to do the utmost to relieve the suffering of burn injured patients wherever they may be and the most effective way to do this is by disseminating knowledge on prevention and treatment.

We also endeavor to set an example of what can be achieved when people of different nationalities, races and religions work together for the benefit of mankind and hold firm to the message of Mahatma Gandhi that "you must be the change you want to see in the World".

\section{T. Potokar, Shobha Chamania*, Shariq Ali** Welsh Centre for Burns and Plastic Surgery, Swansea, Wales, UK, *Choithram Hospital and Research Center, Indore, India, ${ }^{* *}$ Burns Centre Civil Hospital and Dow University of Health Sciences, Karachi, Pakistan}

Address for correspondence: Tom Potokar, Welsh Centre for Burns and Plastic Surgery, Morriston Hospital Swansea Wales, United Kingdom. E-mail: tom.potokar@swansea-tr.wales.nhs.uk 